\title{
AMINO-FORMALDEHYDE RESINS. PROPERTIES AND APPLICATION TO REMOVE CONTAMINANT METAL IONS. AN OVERVIEW
}

\author{
BERNABÉ L. RIVAS * AND ESTEBAN MARTÍNEZ \\ Polymer Department, Faculty of Chemistry, University of Concepción, Concepcion, Chile.
}

\begin{abstract}
The global production of formaldehyde urea resins (UF) for 2019 was 6 million ton/year, being the largest use in the forestry industry in the production of MDP and MDF boards. It is in the resin industry's interest to develop other applications of these polymers.

The possible metal ion separation properties of commercial resins of the type urea-formaldehyde resins (UF), melamine-urea-formaldehyde resins (MUF), and formaldehyde melamine (MF) are achieved by modifying with functional groups.

The metal retention properties are determined by batch method in aqueous phase where the purified and sieved solid resin is put into contact with the metal ions at different $\mathrm{pH}$, controlling temperature and ion force. The most studied metal ions are metal ions like $\mathrm{Cu}$ (II), $\mathrm{Co}$ (II), $\mathrm{Cd}$ (II), $\mathrm{Zn}$ (II), $\mathrm{Cr}$ (III), $\mathrm{Hg}$ (II) and $\mathrm{Cr}$ (VI).

The aim to contribute with this overview, is demonstrate the use of these modified resins to remove metal ions and also the potential application to use them as support to include new functional groups to increase the efficiency and affinity, Moreover, it is motivated by the production in our country of these resins and investigate possible applications in this research field.
\end{abstract}

Keywords: Amino-formaldehyde resins, separation process, environment, metal ions, removal.

\section{INTRODUCTION}

Eugenol is part of the family of allylbenzenes, which in turn are part of the Global production of formaldehyde urea resins (UF) for 2019 was estimated at 6 million ton/year, being the largest use in the forestry industry in the production of MDP and MDF boards, therefore the entire resin, logistics, production, R\&D etc. Industry is oriented to the optimization of this type of products that are exported and that must constantly comply with environmental regulations especially after the formaldehyde was declared as cancerogenic. In recent years the forestry business in has stopped growing, in some cases some producers have disappeared because they have not been able to compete economically with higher volume producers that achieve better production costs, especially by having their inputs integrated into cellulose plants. That is why chemical resin plants have some production capacity that could meet some new need or requirement, but no longer of the forest area.

In 2014 the Innovation for Development Council (CNID) constituted the "Mining and Development Commission of Chile" developed the Technology Roadmap from 2015 to 2035 [1] identifying five drive nuclei such as relays, smelting and mining, mining planning operations, mineral concentration and hydrometallurgy, which require enabling cores such as human capital, suppliers and innovation and intelligent mining, reaching the production of 8.5 million tonnes of copper in 2035.

Within the technological search of flotation were found 88 patents of which 2 of them are based on amino aldehyde resins used in the separation process. "Modified amine-aldehyde resins and uses thereof in separation processes" [2] and "Amine-aldehyde resins and uses thereof in separation processes" [3]. They describe the removal of a variety of solids and/or ionic species from liquids that are suspended or dissolved. These resins are especially useful as depressants in foam flotation processes for the benefit of obtaining materials valued as (bitumen, coal, kaolin clay) of impurities such as sand. Resins are also used in the treatment of aqueous suspensions to remove solid particles or to remove metal ions in water purification.

Currently in flotation processes are commonly used as depressant agents the cyanide-zinc complex that depresses copper sulfides (calcosite), ferrocyanide, and Nokes reagents, sodium hydroxide plus phosphorus pentasulfide that depresses copper sulfides, fluorosilicate, and ion fluoride to depress quartz and silicates. Organic depressants are commonly used in the flotation of non-metallic minerals and can be categorized as polyglycol ether, polysaccharides (starch, carboxymethyl cellulose, dextrin, and rubber), and polyphenols (tannin, crack and mimosa). The greatest application is in the depression of calcite, dolomite, talc, and pyrophyte, although starch and dextrin are used to depress galena, pyrite, and molybdenite. The main process of adsorption is hydrogen bond although polysaccharides seem to react especially with iron minerals, thus favoring their use for flocculation and depression of these minerals.
In the copper mining industry in the flotation process stage several reagents with foaming functions, collectors, depressants and $\mathrm{pH}$ modifiers are used, commonly the depressant reagents used are sodium sulfide $\left(\mathrm{Na}_{2} \mathrm{~S}\right)$, NaHS sodium sulfidrate, $\mathrm{NaCN}$ sodium cyanide, lime, and chromates and dichromates, $\mathrm{K}_{2} \mathrm{Cr}_{2} \mathrm{O}_{7}$.

\section{CONTAMINATION BY METALS}

The presence of a large number of chemical and biological pollutants is expected in drinking water. This pollution of water resources caused by an increasing population occurs via the use and disposal of chemical, agricultural, animal products, and industrial waste.

The major percentage of inorganic substances found in groundwater is derived from natural origins. However, significant amounts are also a result of the human activities. Thus, the removal/remediation of these substances is necessary. Over the last few years, discarding solid and/or liquid waste products containing heavy metals emanating from industrial processes has received much attention, and consequently, legislation for the protection of the environment has gradually become more strict $[4,5]$. Contamination of the environment by heavy metals is a growing concern because are highly toxic at low concentrations and can accumulate in living organisms, causing several disorders and diseases. According to the World Organization of Health (WHO), the cationic metals of most immediate concern are aluminum, cadmium, chromium, cobalt, copper, iron, lead, magnesium, nickel, and zinc, whereas arsenic and hexavalent chromium as anionic pollutants [4].

Various pollutants such as organic compounds, heavy metals, and oxyanions emerge as a result of industrial applications. Especially organic pollution combining with heavy metals should be taken into consideration as an important problem in terms of environment. Since these pollutants and their derivatives are carcinogenic and have toxic effect on humans, animals as well as aquatic plants and animals, they should be removed via wastewater treatment methods. According to that, several methods and materials have been developed for environmental clean-up and remediation of metal ions from wastewater and synthetic wastewater, such as adsorption, also by using biomaterials, nanocomposites, ion exchange, membrane separation, solvent extraction [4-17]. All methods have advantages and disadvantages, however, ion exchange and adsorption are well studied since they are efficient for heavy metal recovery and water deep purification. Thus, removal of heavy metals from aqueous solutions by using adsorption method with low-cost adsorbents might be both economic and effective adsorption is considered to be one of the most efficient techniques because of its good operational flexibility, high efficiency, and excellent reusability [20-22, 22.a, 22.b, 22.c]. During the adsorption, heavy metals are transferred from wastewater and adhered to the surface of the adsorbent by the physical and/or chemical interactions between them. 
In recent years, the researchers have tried various composite production methods in order to activate the adsorbents. It was observed that formation of different composites from natural adsorbents activated them and their adsorption capacities increased [23-24].

\section{REMOVAL BY AMINO-FORMALDEHYDE RESINS}

Modified resins [24-26] to improve mechanical properties, but other applications are also described to remove a wide variety of solids and / or ionic species from the liquids in which they are suspended and / or dissolved. These modified resins are especially useful as foam buoyancy depressants, to treat aqueous liquid suspensions to facilitate the removal of solid particles, as well as the removal of metal ions in water purification. Modified resins comprise a base resin that is modified with a coupling agent, which is highly selective for binding to metal ions.

\subsection{Urea formaldehyde Resins. UF Resins}

3.1.1 UF resins modified with thiourea for separation $\mathrm{Au}(\mathrm{III}), \mathrm{Cu}(\mathrm{II})$, and $\mathrm{Zn}(I I) \cdot[27]$

In this research proceed to synthesize two resins, one totally ureaformaldehyde and another totally thiourea formaldehyde. The resins are carried up to $100 \%$ conversion or gelled. Resins were characterized by elemental analysis and FT-IR spectroscopy. The metal ion retention capacity was studied through a column with resin to which $\mathrm{Au}(\mathrm{III}), \mathrm{Cu}$ (II), and $\mathrm{Zn}$ (II) solutions are passed on to constant flow pump. The concentrations of the metals in solution are determined by atomic absorption spectroscopy (AAS). Studies are carried out at different $\mathrm{pH}$ and the metal retention capacity of both resins is determined.

Figure 1 represents the general mechanism for obtaining a UF, MUF or MF resin. It shows the following: (1) the methylolation reaction of urea with formaldehyde in acidic or basic medium is carried out, and then in (2) and (3) begin the condensation reaction. Side reactions that generate rearrangement are explained in eqs. (4) and (5).

\section{Hydroxymethylolation}<smiles>[X]C(N)=[V]C=O</smiles>

$\mathrm{X}$ : S (Thiourea) or O (Urea)<smiles>[X]C(N)NCO</smiles>

\section{Condensation}<smiles>[X]C(NCCCC)NCNC(=[X])NCO</smiles><smiles>[X]C(N)NCO</smiles>

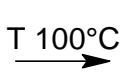<smiles>[X]C(N)NCOCNC([X])N</smiles><smiles>[X]C(NC)NCOCNC([X])NC</smiles>

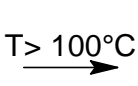<smiles>[X]C(NC)NCNC([X])NC</smiles><smiles>C=O</smiles><smiles>[X]C(NC)NCC</smiles><smiles>[X]C(C)(NC)NC</smiles>

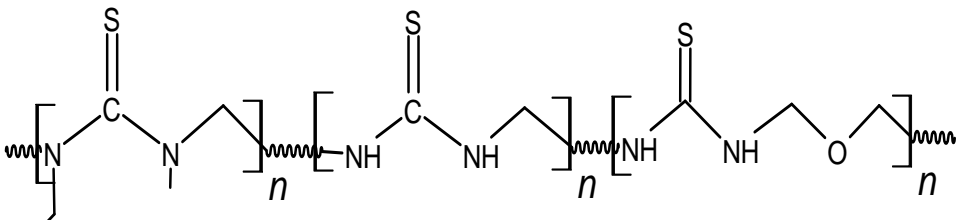

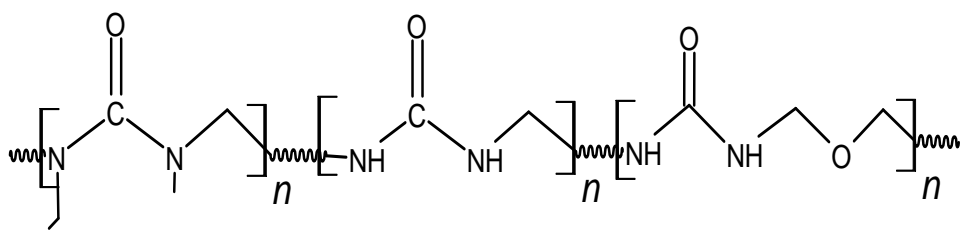

Figure 1. General scheme of UF resin reaction mechanism and comparison of the general structures [27]. 
Figure 2 shows adsorption curves for $\mathrm{Au}$ (II), $\mathrm{Cu}$ (II), and $\mathrm{Zn}$ (II) obtained for $\mathrm{TF}$ resin and UF. $1 \mathrm{~g}$ of resin at a flow of $0.74 \mathrm{BV} / \mathrm{min}$. They see a noticeable effect on the substitution of a functional group.

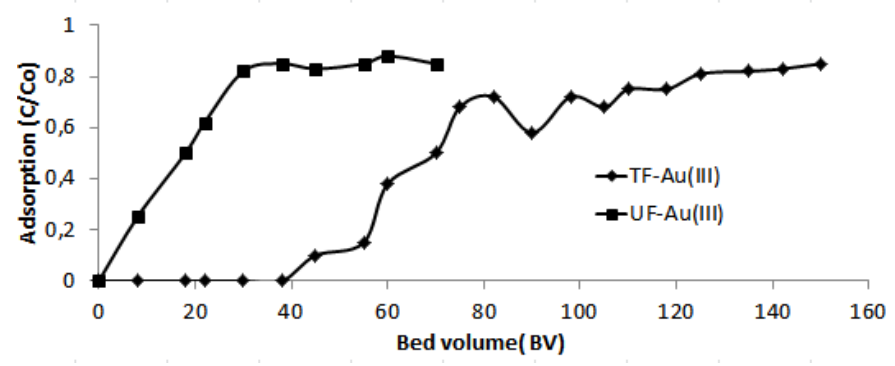

Figure 2. Adsorption curves for $\mathrm{Au}(\mathrm{II}), \mathrm{Cu}(\mathrm{II})$, and $\mathrm{Zn}$ (II) obtained for TF and UF resin. [27].

3.1.2 Foamed urea-formaldehyde microspheres for removal of heavy metals from aqueous solutions [28]

Because a high degree of crosslinking can make it difficult for ions to penetrate the chelating surface of the resins. The other authors [28] modified the gelling mechanism, achieving microspheres.

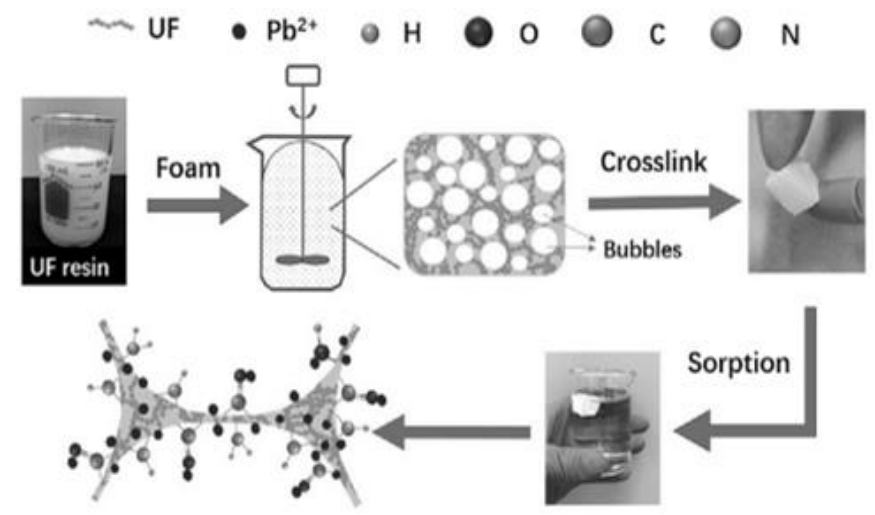

Figure 3. Foamig method to fabricate UF resins microspheres.[30].

A simple foaming method (see Fig 3) was applied to fabricate urea formaldehyde (UF) microspheres with crosslinked porous structures for environmental remediation of heavy metals. The specific surface area and average pore radius of the resultant foamed UF microspheres were $11-29 \mathrm{~m}^{2} / \mathrm{g}$ and $11-25 \mathrm{~nm}$, respectively, which increased with the increasing molar ratio of formaldehyde to urea. All the foamed UF microspheres showed good removal of heavy metals ions $(\mathrm{Pb}(\mathrm{II}), \mathrm{Cu}(\mathrm{II})$, and $\mathrm{Cd}(\mathrm{II}))$ in both single- and mixed-metal solutions. Further investigations of $\mathrm{Pb}$ (II) adsorption on a selected UF microspheres showed fast kinetics and relatively high adsorption capacity (21.5 $\mathrm{mg} \mathrm{g}^{-1}$ ), which can be attributed to the mesoporous structure and abundance of oxygen surface functional groups of the microspheres.

Both experimental and model results showed that chelation or complexation interactions between $\mathrm{Pb}(\mathrm{II})$ and the surface functional groups were responsible to the strong adsorption of the heavy metal ions on the microspheres. Hydrochloric acid $(0.05 \mathrm{M})$ successfully desorbed $\mathrm{Pb}$ (II) from the postadsorption microspheres for multiple times and the regenerated microspheres showed high $\mathrm{Pb}$ (II) removal rates (>96\%) in five adsorption-desorption cycles. With many promising advantages, foamed UF microspheres show great potential as a wastewater treatment agent for heavy metal removal. In table 1, a summary of their adsorption capacity and a comparison with similar adsorbents is made.

Table 1. Summary of the $\mathrm{Pb}$ (II) adsorption capacity of various adsorbents. [28]

\begin{tabular}{|l|c|c|}
\hline Adsorbent & $\begin{array}{c}\text { Pb(II) sorption } \\
\text { capacity }\left(\mathrm{mg} \mathrm{g}^{-1}\right)\end{array}$ & Reference \\
\hline Melamin-Formaldehyde resin microspheres & 4.9 & {$[29]$} \\
\hline Betonite/Thiourea-formaldehyde composite & 13.38 & {$[30]$} \\
\hline Poly(Anthranilic acid-2-aminopyridine-formaldehyde) & 6.54 & {$[31]$} \\
\hline Foamed Urea Formaldehyde & 21.5 & {$[28]$} \\
\hline
\end{tabular}

4968
3.1.3 Synthesis and Characterization of Antibacterial Polychelates of UreaFormaldehyde Resin with $\mathrm{Cr}(\mathrm{III}), \mathrm{Mn}(\mathrm{II}), \mathrm{Fe}(\mathrm{III}), \mathrm{Co}(\mathrm{II}), \mathrm{Ni}(\mathrm{II}), \mathrm{Cu}(\mathrm{II})$, and Zn(II) Metal Ions. [32]

Uses and applications of UF resins already formed as polyquelates have also been reported as for example in antibacterial activity. This research studies the reaction between urea and formaldehyde with the aim of preparing polyquelates of $\mathrm{Cr}(\mathrm{III}), \mathrm{Mn}$ (II), $\mathrm{Fe}$ (III), $\mathrm{Co}(\mathrm{II}), \mathrm{Ni}$ (II), $\mathrm{Cu}$ (II), and $\mathrm{Zn}$ (II) as shown in Figure 4. The compounds were characterized by elemental analysis, FT-IR, ${ }^{1} \mathrm{H}-\mathrm{NMR}$, XPS, TGA, and magnetic susceptibility. A ratio (metal/ligand) 1:1.15 was found, and greater thermal stability to complexes versus UF resin, the congenital susceptibility allows to confirm the geometry of the complexes. The bactericide activity of polychelates is investigated with diffusion methods in agar, found similar to stable drugs such as ciprofluoxacin or ampicillin (see Table 2).

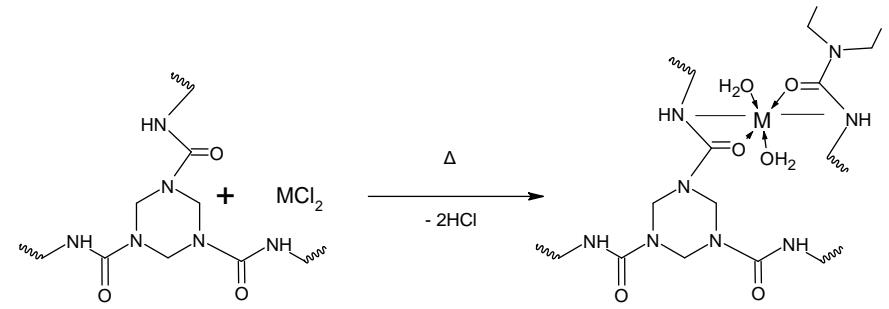

Figure 4. Scheme of obtaining polychelates from a UF resin, where $\mathrm{M}=$ $\mathrm{Mn}(\mathrm{II}), \mathrm{Co}(\mathrm{II}), \mathrm{Ni}(\mathrm{II}), \mathrm{Cu}(\mathrm{II})$ and $\mathrm{Zn}$ (II) [32]

Table 2. Antibacterial activity ligand UFR and its polychelates with metal ions $\mathrm{Mn}(\mathrm{II}), \mathrm{Fe}(\mathrm{III}), \mathrm{Co}(\mathrm{II}), \mathrm{Ni}(\mathrm{II})$, and $\mathrm{Cu}(\mathrm{II})$ obtained from UF resins [32].

\begin{tabular}{|l|c|c|c|c|c|}
\hline \multirow{2}{*}{ Compound } & \multicolumn{5}{c|}{ Antibacterial activity $^{\mathbf{a}}$} \\
\cline { 2 - 7 } & E.Coli & S. aureus & B. megaterium & P.vulgaris & B.Subtilis \\
\hline $\mathrm{C}_{8} \mathrm{H}_{11} \mathrm{~N}_{4} \mathrm{O}_{2}$ & 5 & 8 & 7 & 6 & 10 \\
\hline$\left(\mathrm{C}_{8} \mathrm{H}_{9} \mathrm{~N}_{4} \mathrm{O}_{2} \mathrm{Mn} \cdot 2 \mathrm{H}_{2} \mathrm{O}\right)_{n}$ & 12 & 11 & 14 & 13 & 11 \\
\hline$\left(\mathrm{C}_{8} \mathrm{H}_{9} \mathrm{~N}_{4} \mathrm{O}_{2} \mathrm{Fe} \cdot 2 \mathrm{H}_{2} \mathrm{O}\right)_{\mathrm{n}_{n} \cdot{ }_{n} \mathrm{Cl}}$ & 10 & 15 & 12 & 12 & 14 \\
\hline$\left(\mathrm{C}_{8} \mathrm{H}_{9} \mathrm{~N}_{4} \mathrm{O}_{2} \mathrm{Co} \cdot 2 \mathrm{H}_{2} \mathrm{O}\right) n$ & 18 & 10 & 9 & 14 & 13 \\
\hline$\left(\mathrm{C}_{8} \mathrm{H}_{9} \mathrm{~N}_{4} \mathrm{O}_{2} \mathrm{Ni} \cdot 2 \mathrm{H}_{2} \mathrm{O}\right)_{n}$ & 13 & 17 & 11 & 12 & 15 \\
\hline$\left(\mathrm{C}_{8} \mathrm{H}_{9} \mathrm{~N}_{4} \mathrm{O}_{2} \mathrm{Cu} \cdot 2 \mathrm{H}_{2} \mathrm{O}\right)_{n}$ & 16 & 14 & 13 & 14 & 19 \\
\hline DMSO & - & - & - & - & - \\
\hline $\mathrm{Ciprofloxin}$ & 25 & 24 & 20 & 22 & 22 \\
\hline Ampicillin & 18 & 22 & 15 & 20 & 20 \\
\hline Kanamycin & 26 & 25 & 22 & 26 & 25 \\
\hline
\end{tabular}

0-5 = Inactive; 5-10 = mildly active ; 10-15 = moderately active; $>15=$ highly active. Ciprofloxacin, ampicilin,and kanamycin were udes as standard drugs. DMSO was udes as a control.

a Zone of inhibition in $0-25 \mathrm{~mm}$ at a concentration of $25 \mu \mathrm{g} \mathrm{mL}-1$

\subsection{Melamine Urea Formaldehyde Resins. MUF Resins}

An example of separation of $\mathrm{Cr}((\mathrm{III})$ and $\mathrm{Cr}$ (IV) using MUF resin [33] which can be considered as a UF resin modified with melamine to be converted into MUF resin. In this work it is used to preconcentrate and separate these ions.

\subsubsection{Speciation of $\mathrm{Cr}(\mathrm{III})$ and $\mathrm{Cr}(\mathrm{VI})$ using melamine-urea-formaldehyde resins and FAAS. [33]}

A method is described for the quantitative preconcentration and separation of trace chromium in water by adsorption on melamine-urea-formaldehyde resin. $\mathrm{Cr}(\mathrm{VI})$ is enriched from aqueous solutions on the resin. After elution the $\mathrm{Cr}(\mathrm{VI})$ is determined by Flame atomic absorption spectroscopy (FAAS). The capacity of the resin is maximal at $\mathrm{pH} 2$. Total chromium can be determined by the method after oxidation of $\mathrm{Cr}(\mathrm{III})$ to $\mathrm{Cr}(\mathrm{VI})$ by hydrogen peroxide. The relative standard deviations (10 replicate analyses) for $10 \mathrm{mg} \mathrm{L}^{-1}$ levels of $\mathrm{Cr}(\mathrm{VI}), \mathrm{Cr}(\mathrm{III}$, and total chromium were $1.5,3.5$, and $2.8 \%$ respectively. The procedure has been applied to the determination and speciation of chromium in lake water, tap water, and chromium-plating baths. 
The preparation of MUF resin is described [34] 1 mol melamine, 1 mol of urea, and 6.5 mole formaldehyde (35\% solution) in a ball, being mixed to reflux for 15 min with magnetic agitation until a transparent gel is achieved, $\mathrm{NaOH}$ is added to $10 \%$ slowly until the gel is white and insoluble at $\mathrm{pH} 10$. The resin is washed and dried sifted at 350-853 um and characterized by FT-IR spectroscopy.

The tests are performed in column and procedure for speciation of $\mathrm{Cr}(\mathrm{III})$ and $\mathrm{Cr}(\mathrm{VI})$. Selection of optimal $\mathrm{pH}$ of preconcentration portions $(25 \mathrm{~mL})$ of $10 \mathrm{mg}$ $\mathrm{L}^{-1} \mathrm{Cr}(\mathrm{VI})$ solution, at $\mathrm{pH}$ ranging from 1 to 9 were shaken with $0.5 \mathrm{~g}$ of resin for $2 \mathrm{~h}$. After filtration, the chromium adsorbed on the resin was eluted with $0.1 \mathrm{M}$ sodium hydroxide, and determined by AAS. At $\mathrm{pH}$ 2-2.5 was found optimum for the selective sorption of $\mathrm{Cr}(\mathrm{VI})$ (see Fig. 5).

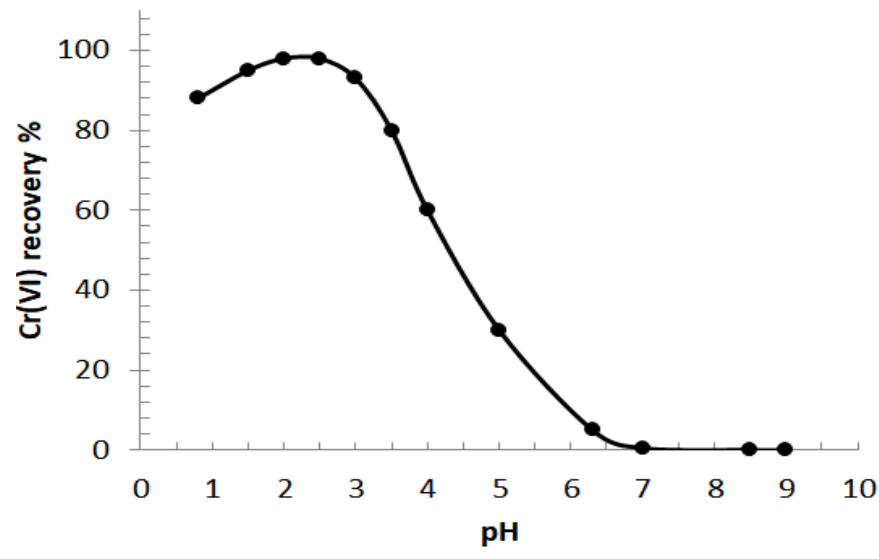

Figure 5. Recovery of chromium as a funtion of pH [33].

As shown in Fig. 5, optimum efficiency of enrichment was obtained at $\mathrm{pH}$ $2 \pm 2.5$. There was no interference by the diverse ions which were examined (see Table 3).

Table 3. Effect of foreing ions (all $100 \mathrm{mg} \mathrm{L}^{-1}$ ) on the adsorption of $\mathrm{Cr}(\mathrm{VI})$ ( $20 \mathrm{mg} \mathrm{L}^{-1}$ ) [33].

\begin{tabular}{|c|c|}
\hline Foreing ion & Recovery of $\mathbf{C r}(\mathbf{V I})(\boldsymbol{\%})$ \\
\hline $\mathrm{Fe}^{3+}$ & 100 \\
\hline $\mathrm{Zn}^{2+}$ & 99.8 \\
\hline $\mathrm{Cr}^{3+}$ & 99.5 \\
\hline $\mathrm{Cl}^{-}$ & 100 \\
\hline $\mathrm{SO}_{4}{ }^{2-}$ & 100 \\
\hline $\mathrm{NO}^{3-}$ & 99.5 \\
\hline $\mathrm{PO}_{4}{ }^{3-}$ & 98.5 \\
\hline $\mathrm{Cd}^{2+}$ & 99.9 \\
\hline $\mathrm{Ni}^{2+}$ & 99.7 \\
\hline
\end{tabular}

It was shown that good sensitivity and selectivity for the determination of chromium can be attained by using preconcentration with melamine-ureaformaldehyde resin and subsequent determination of chromium in the eluate. This resin has some advantages, its low toxicity and low cost relative to melamine-formaldehyde resin [37]. Known extraction methods are frequently very slow and tedious and moreover are less sensitive than the proposed method. Other pre-concentration methods such as co-precipitation, use of chelating agents and electrodeposition on a graphite tube are also complicated and do not give an improvement in sensitivity. The method studied in this work has good precision and accuracy and matrix effects are absent. It can be concluded that the speciation of chromium is possible by use of the proposed pre-concentration method.

\subsection{Melamine Formaldehyde Resins. MF Resins}

The main applications in the wood industry for melamine formaldehyde resins is in the production of impregnating papers, whose paper is adhered to the surface of the wood board with beautiful finishes in different colors. This type of resins have limited solubility and are mostly colorless.
3.3.1 Melamine-formaldehyde-NTA chelating gel resin: Synthesis, characterization and application for copper(II) ion removal from synthetic wastewater. [36]

Selective removal of $\mathrm{Cu}$ (II) from wash water using melamine-formaldehyde MF resins modified with triethic nitrile acid (NTA) has been reported [39]. The effect of preparation conditions such as (temperature, acidity, water content) and resin characteristics (water recovery, stiffness, NTA functionality and porosity) was studied. It was found that at $\mathrm{pH} 1.3$ and $150^{\circ} \mathrm{C}$ are the best resin preparation conditions. The resins were characterized by FT-IR spectroscopy, CHNO elemental analysis, and nitrogen adsorption (BET), and scanning electron microscopy (SEM), surfaces of $159 \mathrm{~m}^{2} \mathrm{~g}^{-1}$ were achieved.

The simultaneous adsorption of $\mathrm{Co}(\mathrm{II}), \mathrm{Cd}(\mathrm{II}), \mathrm{Zn}(\mathrm{II})$, and $\mathrm{Cu}$ (II) from synthetic washwater solutions were determined by batch process and quantified their content by atomic absorption spectroscopy, a selective adsorption of ion $\mathrm{Cu}$ (II) was observed between $\mathrm{Co}(\mathrm{II}), \mathrm{Cd}(\mathrm{II}), \mathrm{Zn}$ (II), thermodynamic properties were calculated finding that for $\mathrm{Cu}(\mathrm{II})$ it is spontaneous $(\Delta \mathrm{Gads}<0)$, exothermal $(\Delta$ Hads $>0)$, and reversible $(\Delta \operatorname{Sads}<0)$, and reversible $(\Delta \operatorname{Sads}<0)$. Kinetically, the reaction is reversible kinetics of the first order, according to the Langmiur isotherm model the capacity of $\mathrm{Cu}$ (II) is $52.6 \mathrm{mg} \mathrm{g}^{-1}\left(0.083 \mathrm{mmol} \mathrm{g}^{-1}\right.$. Using an EDTA solution, the resin can be regenerated by metal ions. After regeneration it is observed that the capacity decreases due to partial hydrolysis of the functional active groups NTA.

Other chelating groups [44] have been studied in this same type of resins, such as dietary-minopentatic acid (MF-DTPA) (see Fig. 8) in the removal of heavy metals such as $\mathrm{Co}(\mathrm{II}), \mathrm{Cd}(\mathrm{II}), \mathrm{Zn}$ (II), and $\mathrm{Cu}$ (II) and nitro acetic acid (NTA ) [43] during the ratio of melamine-formaldehyde resin in the presence of water using acetone and guaicol as a porogenic mixture in removing $\mathrm{Cu}$ (II) from synthetic wash water. Fig 6 proposes a possible structure of MF-NTA resin. It is also of interest to determine the optimal $\mathrm{pH}$ adsorption since at $\mathrm{pH}$ greater than 6 copper hydroxide is formed.

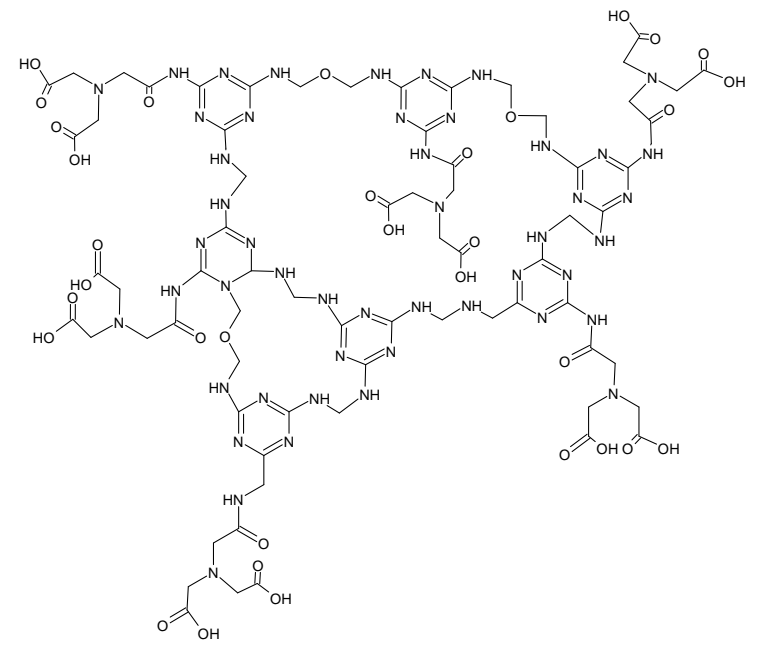

Figure 6. Possible structure of MF-NTA resin [36].

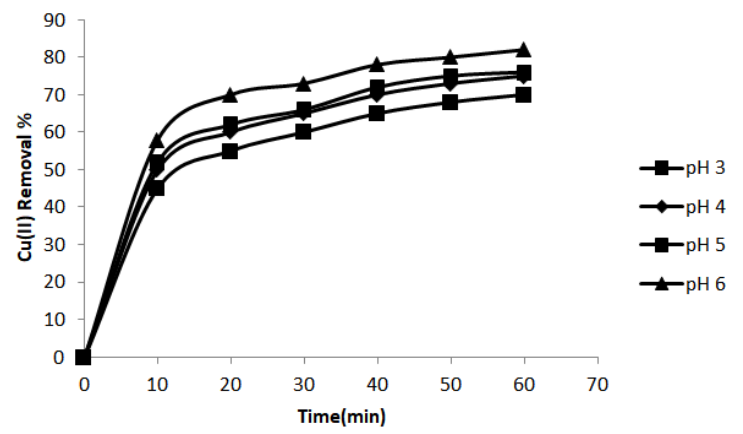

Figure 7. Example of kinetic study [8] of metal retention $\mathrm{Cu}(\mathrm{II})$ at $25^{\circ} \mathrm{C}, 150$ $\mathrm{rpm}$, initial concentration $100 \mathrm{mg} \mathrm{L}^{-1} \mathrm{ppm}$, volume $30 \mathrm{~mL}$, adsorbent gel $0.3 \mathrm{~g}$, $\mathrm{pH}$ values $3,4.5$, and 6.[36]. 
Comparison of the adsorption capacity of MF-NTA resin is shown in Table 4. These are moderate compared to those materials.

Table 4. Comparison of adsorption property, Qo of $\mathrm{Cu}$ (II) MF-NTA. [36]

\begin{tabular}{|l|c|c|}
\hline Material & Qo $\left(\mathrm{mg} \mathrm{g}^{-1}\right)$ & Reference \\
\hline Spirogyra (biomass) & 133.3 & {$[37]$} \\
\hline Raw Kaolinite & 10.78 & {$[38]$} \\
\hline AMA & 7.09 & {$[39]$} \\
\hline PMA & 8.55 & {$[39]$} \\
\hline Chitasan-Cellulose beads & 53.2 & {$[40]$} \\
\hline P(HEMA-co-MAH) & 122.7 & {$[41]$} \\
\hline Polydithiocarbamate( synthetic resin) & 35 & {$[42]$} \\
\hline MF-NTA & 29.7 & {$[36]$} \\
\hline
\end{tabular}

3.3.2 . Preparation and characterization of melamine-formaldehyde-DTPA chelating resin and its use as an adsorbent for heavy metals removal from wastewater [44] .

Melamine-formaldehyde-diethylenetriaminepentaacetic acid (MF-DTPA) resin was prepared as a new adsorbent for removing heavy metals from wastewater effluents. The resin was synthesised by anchoring the chelating agent diethylenetriaminepentaacetic acid (DTPA) to melamine via amide covalent bond during melamine-formaldehyde condensation reaction in an acidic aqueous medium. The effects of reaction parameters (temperature, acidity, and water content) on resin characteristics (water regain, rigidity, DTPA functionality, and porosity) were monitored to specify the best synthesis conditions. The resin was chemically characterized using infrared spectroscopy (FTIR), elemental analysis (EA), thermal programmed decomposition-mass spectrometry (TPD-MS), solidstate ${ }^{13} \mathrm{C}-\mathrm{NMR}$ and ${ }^{15} \mathrm{~N}-\mathrm{NMR}$ spectroscopy, and was morphologically characterized using $\mathrm{N}_{2}$ gas adsorption/desorption (BET analysis) and field emission-scanning electron microscopy (FESEM).

The water regain factor was also calculated to determine hydrophilic character of the resin. The simultaneous adsorption performance of MF-DTPA resin towards selected heavy metals, $\mathrm{Co}(\mathrm{II}), \mathrm{Cd}(\mathrm{II}), \mathrm{Zn}$ (II), and $\mathrm{Cu}(\mathrm{II})$, was discussed. (see figure 8). Quantitative analysis for adsorption was conducted using atomic absorption to investigate the kinetics, adsorption isotherm and thermodynamics of the removal process considering $\mathrm{pH}$, initial concentration, temperature, and contact time as controlling parameters. The mechanism of adsorption was suggested based on experimental results. This work shows the potential application of the MF-DTPA.

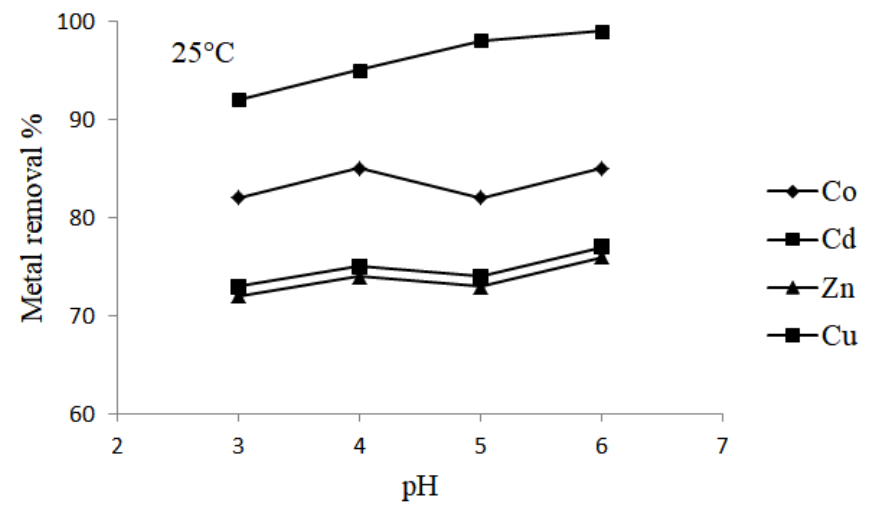

Figure 8. Example of kinetic study of metal retention at different $\mathrm{pH}$ (top) and lower, study of metal removal in a mixture at different $\mathrm{pH}$. [44]

In the figure 9 is suggested the formation mechanism of MF-DTPA resin from melamine, formaldehyde and DTPA.

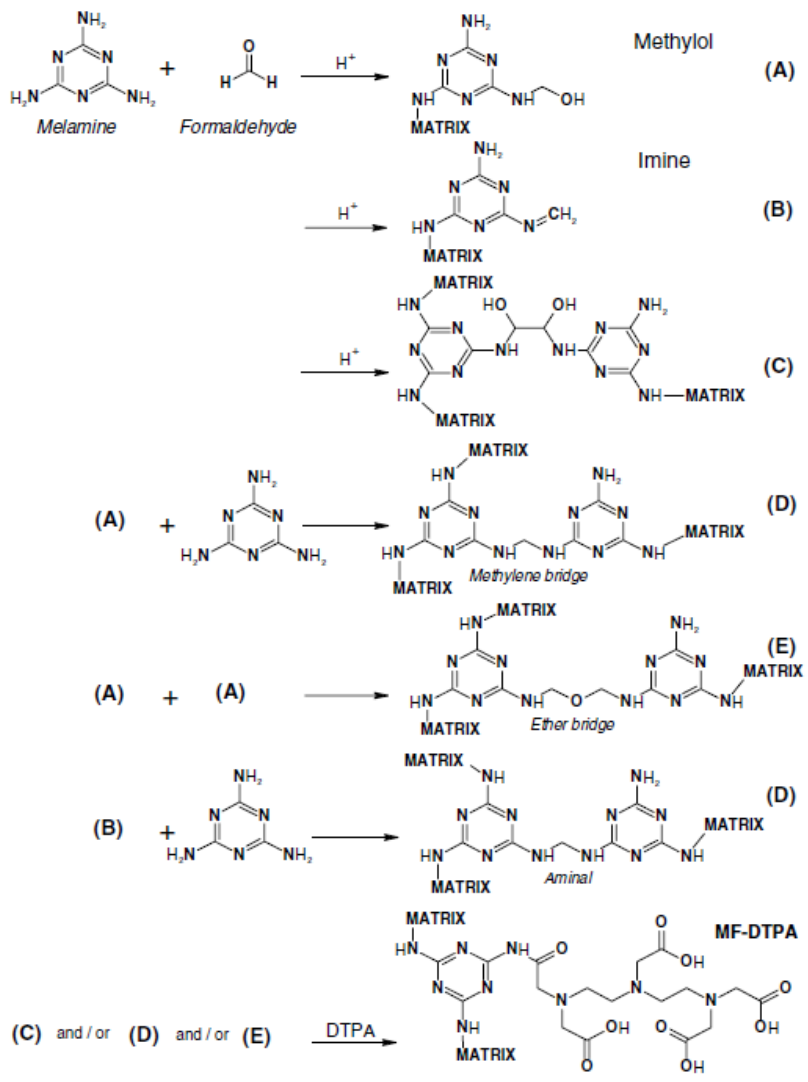

Figure 9. Suggested formation mechanism of MF-DTPA resin from melamine, formaldehyde, and DTPA precursors under acid conditions [44].

3.3.3 Extraction and separation studies of silver (I) and copper (II) from their aqueous solution using chemically modified melamine resins. [45]

Two modified melamine resins has been prepared and investigated, the modification process took place through the treatment with thiourea to produce $\mathrm{R} 1$ or tetraoxalyl ethylenediamine to produce R2. The adsorption behaviour of the obtained resins towards $\mathrm{Ag}(\mathrm{I})$ and $\mathrm{Cu}$ (II) from their aqueous solutions has been studied using batch method.

The experimental part was done : the resins was prepared from the reaction of melamine, thiourea ( or tetraoxalylethylenediamine) and formaldehyde at molar ratio of (1.5: 1:1) respectively and aqueous media at $\mathrm{pH}$ 9. The mixture was heated at $75-90{ }^{\circ} \mathrm{C}$ for $6 \mathrm{~h}$, the precipitate or gel particles is washed, and dried. Both resins were characterized using, water regain, surface area, pore size, FTIR spectra, and elemental analysis. The structures proposed are shown in figure 10.

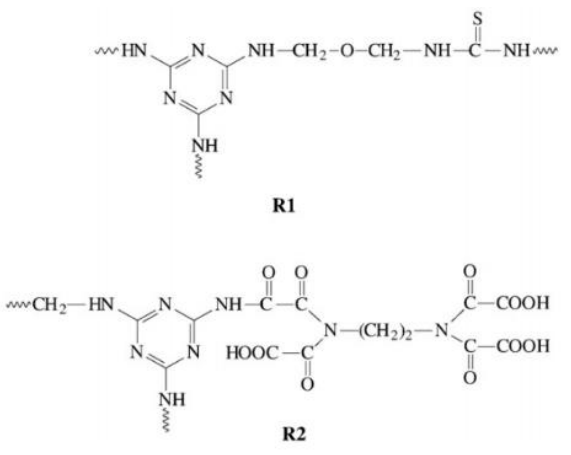

Figure 10. Proposed structures of the studied chelating resins. [45]

Uptake measurements was done, studyng de effect of equilibruim $\mathrm{pH}$ on the uptake, selectivity studies, kinetic, adsoprtion isotherms, column equilibrium procedure, and elution. The main adsorption results for different metal ions and conditions are summarized in figure 11 . 


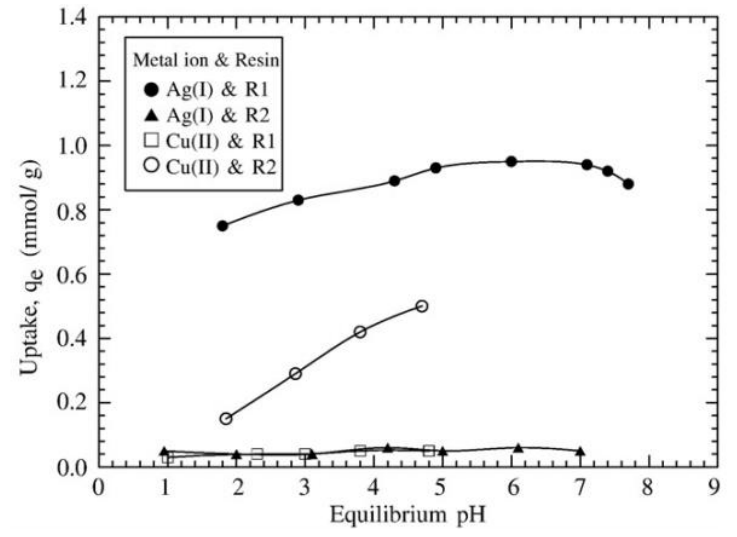

Figure 11. Effect of $\mathrm{pH}$ on the uptake of $\mathrm{Ag}(\mathrm{I})$ by $\mathrm{R} 1$ and $\mathrm{Cu}(\mathrm{II})$ by $\mathrm{R} 2$ from initial concentration $1 \times 10^{-2} \mathrm{M}$ at $25^{\circ} \mathrm{C}$ [45].

The obtained resins were tested for selective separation between $\mathrm{Cu}(\mathrm{II})$ and $\mathrm{Ag}(\mathrm{I})$ from their binary mixtures. The figure 11 showed a Resin $\mathrm{R} 1$ has a high selectivity towards $\mathrm{Ag}$ (I) from $\mathrm{Cu}$ (II) solution, while $\mathrm{R} 2$ gave promising results for the selective separation of $\mathrm{Cu}(\mathrm{II})$ from $\mathrm{Ag}(\mathrm{I})$ solution.

The explanation of the mechanism of adsorption of $\mathrm{Ag}(\mathrm{I})$ of $\mathrm{R} 1$ is shown in the figure 12 using the theory of Hard and Soft Acid and Bases (HSAB) [46]. The sulphur and the nitrogen atoms in thiourea moiety have an easily polarizable lone pairs of electrons and is considered as a "soft base", which would have a tendency to create complex with silver ions (considered "soft acids"). HSAB theory confirms that, the selective resins containing $\mathrm{N}$ or $\mathrm{S}$ donor atoms interact strongly with soft acids like $\mathrm{Ag}(\mathrm{I})$ even in the presence of high concentration of protons. The observed decrease in the uptake of $\mathrm{Ag}(\mathrm{I})$ prior to initial $\mathrm{pH} 8$ may be due to the masking of $\mathrm{Ag}(\mathrm{I})$ ions in the form of soluble anions. At $\mathrm{pH}>8$, almost all of the $\mathrm{Ag}(\mathrm{I})$ ions are precipitated in the form of $\mathrm{AgOH}$ [47]. It is also worth mentioning that the equilibrium $\mathrm{pH}$ is lower than initial $\mathrm{pH}$ in all studied rang. The released $\mathrm{H}^{+}$can be attributed to the deprotonation of thiol form of thiourea moiety at the end of reaction as shown in fig 12 .

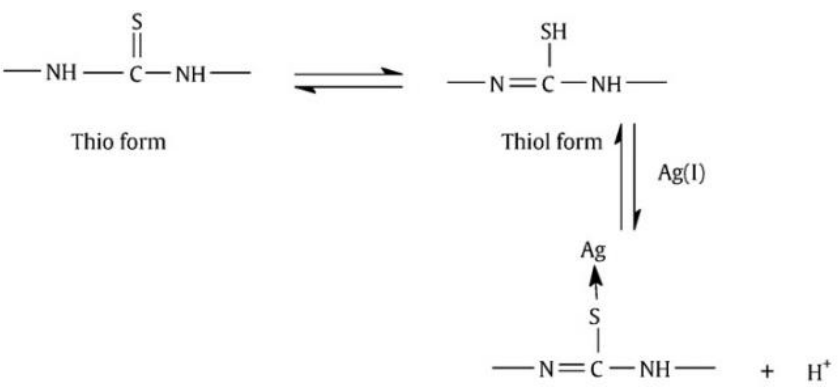

Figure 12. Released $\mathrm{H}^{+}$can be attributed to the deprotonation of thiol form of thiourea [45].

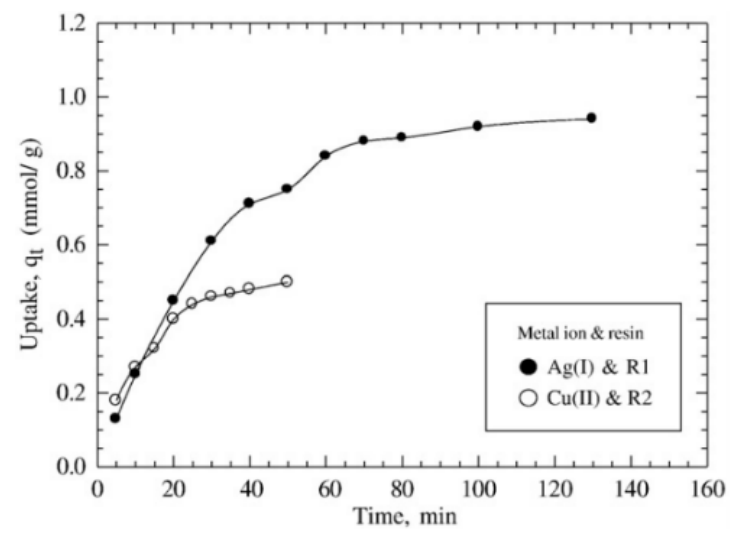

Figure 13. Effect of time on the uptake of $\mathrm{Ag}$ (I) by $\mathrm{R} 1$ and $\mathrm{Cu}$ (II) by $\mathrm{R} 2$ frrom initial concentration $1 \times 10^{-2} \mathrm{M}$ at normal $\mathrm{pH}$ and $25^{\circ} \mathrm{C}$ [45].
The figure 13 showed an effect of time on the uptake. Both kinetic and thermodynamic parameters of the adsorption process were obtained. Thermodynamic data indicated that the adsorption process is an endothermic spontaneous reaction. Kinetic analysis showed also that the adsorption of $\operatorname{Ag}(\mathrm{I})$ on R1 is perfectly fit pseudo-first order model; while the adsorption of $\mathrm{Cu}$ (II) on $\mathrm{R} 2$ is perfectly fit pseudo-second order one. The interaction mechanism between metal ion and active sites has been interpreted as chelation. Durability of resins was estimated from column studies. These parameters indicated that the prepared resins have a good efficiency for repeated use.

3.3.4 Synthesis and application of ion-imprinted resin based on modified melamine-thiourea for selective removal of $\mathrm{Hg}$ (II). [48]

A novel $\mathrm{Hg}$ (II) ion-imprinted resin based on thiourea-modified melamine was manufactured for selective elimination of $\mathrm{Hg}^{2+}$ from aqueous solutions.

The synthesis of $\mathrm{Hg}$-PMTF is carried out using $\mathrm{KSCN}$ in an aqueous and acidic medium, it is refluxed in the presence of melamine at $90{ }^{\circ} \mathrm{C}$ for $1 \mathrm{~h}$, to then cool and purify. The ligand obtained is used to form the complex with $\mathrm{Hg}$ (II) by dissolving the ligand in $\mathrm{MeOH}$ at $80^{\circ} \mathrm{C}$ for $2 \mathrm{~h}$ in the presence of the metal ion. The complex obtained is cross-linked with formaldehyde in a basic medium for $2 \mathrm{~h}$ at $90^{\circ} \mathrm{C}$. The gel obtained is purified and dried. The $\mathrm{Hg}^{2+}$ is removed from the gel in an acid medium. Figure 14 summarizes the stages described.

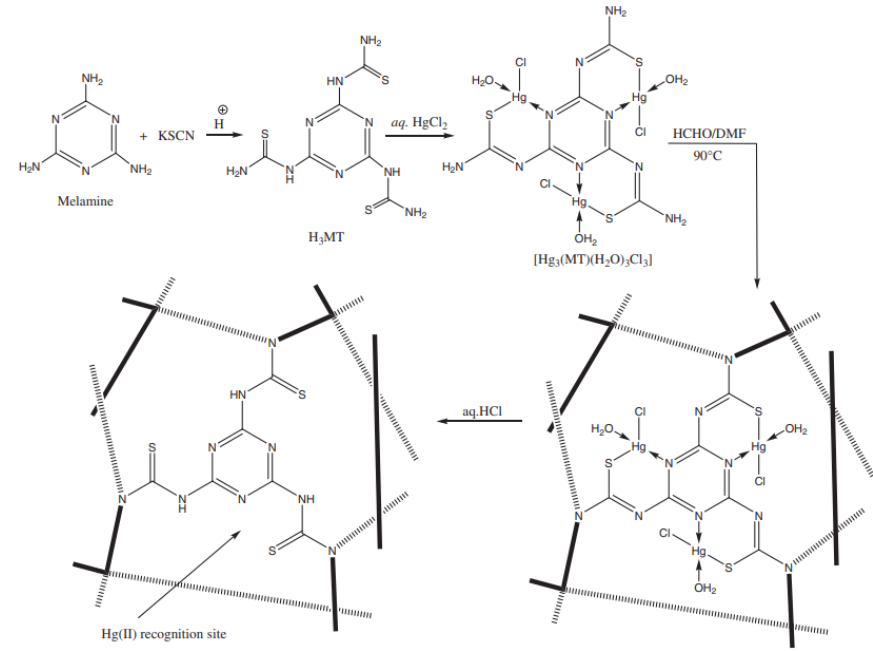

Figure 14. Synthesis of $\mathrm{Hg}$ (II) ion-imprinted resin (Hg-PMTF). [48]

The potential of the prepared resin for selective separation of $\mathrm{Hg}$ (II) ions from aqueous solutions was then evaluated by performing a series of batch experiments, studying in the adsorption the effect of $\mathrm{pH}$, the thermodynamics, kinetics and isotherm, they are also carried out selectivity and reusability study.

Hg-PMTF displayed an obvious rapid removal of $\mathrm{Hg}$ (II) ions with a pseudosecond-order kinetic pattern. In addition, the Langmuir adsorption isotherm model exhibited the best fit with the experimental data with comparatively high maximum adsorption capacity $\left(360.5 \mathrm{mg} \mathrm{g}^{-1}\right)$.

In general, the prepared resin shows a high adsorption capacity when compared to the other recently studied adsorbents (see Table 5).

Table 5. Maximum adsorption capacities for adsorption of $\mathrm{Hg}$ (II) onto various adsorbents. [48]

\begin{tabular}{|l|c|c|}
\hline Adsorbent & $\mathbf{q}_{\max }\left(\mathbf{m g ~ g}^{-1}\right)$ & Reference \\
\hline Polyamine chelating resins & 340 & {$[49]$} \\
\hline $\mathrm{Fe}_{3} \mathrm{O}_{4} /$ rhodamine/hydrazide & 7.7 & {$[50]$} \\
\hline Thiol-modified ion exchanger & 207 & {$[51]$} \\
\hline Chitosan-phenylthiourea & 135.5 & {$[52]$} \\
\hline Chitosan-thioglyceraldehyde & 98.7 & {$[53]$} \\
\hline $\begin{array}{l}\mathrm{Hg}(\mathrm{II}) \text { ion-imprinted poly(ethylene terephthalate) } \\
\text { fibres }\end{array}$ & 77.51 & {$[54]$} \\
\hline 2-Mercaptopyridine-modified silica & 120 & {$[55]$} \\
\hline Ion-imprinted Hg-PMTF (present study) & 340 & {$[48]$} \\
\hline
\end{tabular}




\section{CONCLUSIONS}

Amino resins modifying the amino part by thiourea, NTA, DTPA, are capable to remove metal ions such as $\mathrm{Au}(\mathrm{II}), \mathrm{Co}(\mathrm{II}), \mathrm{Cd}(\mathrm{II}), \mathrm{Ni}(\mathrm{II}), \mathrm{Mn}$ (II), $\mathrm{Fe}(\mathrm{III}) \mathrm{Cr}(\mathrm{VI})$ $\mathrm{Hg}$ (II), $\mathrm{Cu}(\mathrm{II}), \mathrm{Zn}(\mathrm{II})$, and $\mathrm{Pb}$ (II) in solution. Foam or printed resins achieve better results by achieving greater contact surface and in turn can make several loading and unloading cycles when changing the $\mathrm{pH}$ of the solution. There are greater studies of melamine resins given their better resistance to hydrolysis than urea-based resins that can release formaldehyde, especially since they are resins with an interest in decontaminating. Melamine resins manage to form metal complexes, which have interesting antibacterial properties, which may be of interest in the application as an adhesive in the industry.

Is important conclude that these resins have good properties to modify by other different functional groups in order to remove water-contaminants in order to increase not only the efficiency but the selectivity and to reuse it. It would be important as a new potential applications at world level for these resins which are produced in Chile, particularly in Biobio Region.

\section{ACKNOWLEDGEMENTS}

The authors thank to FONDECYT (Grant No 1190469).

\section{REFERENCES}

1. Desde el Cobre a la Innovación. Roadmap Tecnológico de la Minería 20152035. Fundación Chile. Santiago 2016.

2. Wright J.T., White C.R , Gabrielson K., Hines J.B., Arthur L.M., Cousin M.J.,US 8,011,514 B2, sept. 6,2011.

3. Wright J.T., White C.R., Gabrielson K., Hines J.B., Arthur L.M, Cousin M.J. US 8,757,389 B2. Jun.24, 2014

4. WHO, Guidelines for Drinking-Water Quality, Vol. 1, Third ed., World Health Organization, Geneva, 2004.

5. Rodríguez-Cruz, L. F. Lorenzo, M. Arienzo, M. J. Sánchez-Martín, Sci.Total Env. 2007, 382, 82-92.

6. F. Di Natale, A. Lancia, A. Molino, D. Musmarra, J. Haz. Mat. 2007, 145, 381-390.

7. R.M. Schneider, C.F. Cavalin, M. A. S. D. Barros, C. R. G. Tavares, Chem. Eng. J. 2007, 132, 355-362.

8. H. Demiral, I. Demiral, F. Tumsek, B. Karabacakoglu, Chem. Eng. J. 2008, 144, 188-196.

9. P. Santander, D. Morales, B. L. Rivas, N. Kabay, I. Yilmaz, O. Kusku, Marek Bryjak Polym. Bull. 2017, 74, 2033-2044.

10. M. Arany, B. Jamshidi, M. Dehvari, Pol. J. Chem. Tech. 2013, 15, 2, 40-47.

11. A. Kara, E. Demirbel, Kinetic, Water Air Soil Pollut. 2012, 223, 2387-2403.

12. M. Kowalczyk, Z. Hubicki, D. Kołodyńska, Chem. Eng. J. 2013, 221, 512522 .

13. I. Korus, K. Loska, Desalination 2009, 247, 390-395.

14. I. Ochromowicz, W. Apostoluk, Sep. Purif. Technol. 2010, 72, 112-117.

15. J. Sánchez, B. L. Rivas. J. Chil. Chem. Soc. 2019, 64, 4432.

16. B. Wionczyk, R. Cierpiszewski, A. Mólc, K. Prochaska, J. Hazard. Mat. 2011, 198, 257-268.

17. Rivas B.L., Moreno-Villoslada, I, J. Membr. Sci. 2000, 178, 165-170.

18. Rivas B.L., Maturana H.A., Angew. Makromol. Chem., 1994, 61-74, 220 .

19. Rivas B.L., Pereira E.D., Moreno-Villoslada I., Progr. Polym. Sci. 2003, 28, 173-208 .

20. Mudzielwana, R., Gitari, M. W., Akinyemi, S. A., Msagati, T. A. M., South African J. Chem., 2018, 71(1), 15.

21. Edebali, S.. J. Nanomat., Volume 2015, 2015, Article ID 697026.

22. Yang, J., Yu, M., \& Chen, W. J. of Ind. and Eng. Chem.. 2015, 21, 414422.

a. Azarudeen, Raja S.; Ahamed, Mohamed A. Riswan; Thirumarimurugan, M.; et al. Polym Adv. Technol., 2016 27, 235-24, 2 .

b. Ahamad, Tansir; Naushad, Mu.; Eldesoky, Gaber E.; et al. J. Mol. Liq. 2019, 286, 110951.

c. Ahamad, Tansir; Ruksana; Chaudhary, Anis Ahmad; et al. Int. J. Biol. Macromol. 2019, 134, 180-188.

23. Alhaji, N. M. I., Begum, K. M. T. M. I. Res. J. Pure Appl. Chem., 2015, 5(2), 160 .

24. Moussout, H., Ahlafi, H., Aazza, M., El Akili, C. J. Biol. Macromol., 2018, 108, 1063. (2018)
25. Yuyang Gao, Shaoying Lui, Quinyin Wang, Gongying Wang. J. Appl. Polym. Sci., 2019, 137, 486.

26. H.H. El-Nahas, S.E Abdel Aal, N.H. Thaer, Y.H.Gad, A.M. Dessouki, $J$. Appl. Polym. Sci., 2006, 100, 4491-4498.

27. George Hovakeemian, Ma Mun Absi-Halabi, Shawqui M. LahalLih, $J$. Appl. Polym. Sci., 1989, 38, 727-739.

28. F. Ayca Ozdemir, Birsen Demirata, R. Apak. J. Appl. Polym. Sci., 2009, 112, 3442-3448.

29. Elif Ertan, Mustafa Gülfen, J. Appl. Polym. Sci., 2009, 111, 2798-2805.

30. P. Qu,Y.Li. H.Huanga, G. Wu, J.Chen, F. He, H Wang, B Gao, Chemosphere, 2020, 241, 125004.

31. G. Ming, Chem. Eng. J. 2016, 15, 745-757.

32. S. El-Korashy, J. Cleaner Prod. 2016, 137, 40-50.

33. R. S.Azarudeen, Separation and Purification Technology. 2013, 116, 15 September, Pages 366-377.

34. N. Nishat, S. Ahmad, R. T.Ahamad. J. Appl. Polym. Sci., 2006, 100, 928 936.

35. B. Demirata, Mikrochim. Acta. 2001,.136,143-146.

36. Methoden der Organischen Chemie (Houben-Weyl), Band XIV/1: Makromolekulare Stoffe. Georg Thieme Verlag, Stuttgart 1962. 4. Aufl., Herausgeg. von Eugen Müller; LXIV, 1360 S., 65 Abb., 177 Tab.

37. Encylopedia of Polymer Science and Technology. Wiley, New York. 1965, Vol2, p.85.

38. Ahmad Baraka, P.J. Hall, M.J. Helslop. J. Haz. Mat. 2007,140, 86-94.

39. V.K. Gupta, A. Rastogi, V.K. Saini, N. Jain, J. Colloid Interf. Sci. 2006, 296, 59-63.

40. O. Yavuz, Y. Altunkaynak, F. Güzel, Water Res. 2003, 37, 948-952.

41. S. Rengaraj, Y. Kim, C.K. Joo, J. Yi, J. Colloid Interf. Sci. 2004, 273, 14 21.

42. N. Li, R. Bai, Sep. Purif. Technol. 2005, 42 237-247.

43. R. Say, B. Garipcan, S. Emir, S. Patır, A. Denizli, Colloids Surf. 2002, A196, 199-207.

44. P.K. Roy, A.S. Rawat, P.K. Rai, Talanta, 2003, 59,239-246.

45. P.J.Hall, M.J. Heslop A. Baraka. Water Pollution VII. 2006, 95, 519.

46. Ahmad Baraka, P.J. Hall, M.J. Helslop. React. Funt. Polym. 2007, 67, 585600 .

47. M.A.bd El-Ghaffar, Z.H. Abdel-Wahab, K.Z. Elwakeel. Hydrometallurgy. 2009, 96, 27-34.

48. Myasoedova, G.V., Antokol'skaya, I.I., Savvin, S.B., Talanta 1985, 2, 1105 1112.

49. Atia, A.A., Donia, A.M., Elwakeel, K.Z., Sep. Purif. Technol. 2005, 43, 4348.

50. M Monier, Nadia H Elsayedc, DA Abdel-Latifa, Polym. Int. 2015, 64, $1465-$ 1474.

51. Qu R, Liu J, Sun C, Zhang Y, Ji C, Yin P, J. Chem. Eng. Data, 2010, 55, 4650-4659.

52. Wang Z, Wu D, Wu G, Yang N, Wu A, J. Haz. Mater. 2013, 244-245, 621627.

53. Dujardin MC, Caze C., Vroman I, React. Funct. Polym. 2000, 43, 123-132.

54. Wang J and Liu F, Chem. Eng. J. 2014, 242, 117-126.

55. Hu X, Li Y, Wang Y, Li X, Li H, Liu X., Desalination.2010, 259, 76-83.

56. Singh DK and Mishra S, Anal. Chim. Acta, 2009, 644, 42-47.

57. Monier M, Int. J. Biol. Macromol. 2012, 50,773-781. 